\title{
PREVALENCIA DE BRUCELOSIS CANINA EN DOS DISTRITOS DE LA PROVINCIA CONSTITUCIONAL DEL CALLAO
}

\author{
Hernán Ramírez L. ${ }^{1}$, Sonia Calle E. ${ }^{2,3}$, Luisa Echevarría C. $^{4}$ y \\ Siever Morales C. ${ }^{2}$
}

\section{AbSTRACT}

The objective of this study was to determine the prevalence of canine brucellosis (Brucella canis) in two districts of the province of Callao. A total of 456 sera were collected from dogs without distinction of breed, sex and age. Samples were analyzed by the Agar Gel Immunodiffusion (AGID) test using B. ovis antigen. The results indicated that $15.6 \pm 3.3(71 / 456)$ of sampled animals were positive. No statistical differences were found due to district, breed, sex or age; however, differences were found $(\mathrm{p}<0.05)$ beetween dogs with and without reproductive history (26.5 and $8.6 \%$ respectively).

Key words : B. canis, canine brucellosis, AGID, B. ovis, prevalence, zoonoses

\section{Resumen}

El objetivo del presente estudio fue determinar la prevalencia de brucelosis canina (Brucella canis) en dos distritos de la Provincia Constitucional del Callao. Se recolectaron 456 sueros de perros sin distinción de sexo, raza y edad, que se analizaron mediante la prueba de Inmunodifusión en Gel de Agar (IDGA) con antígeno de B. ovis. Se encontró una prevalencia de $15.6 \pm 33 \%$ (71/456). No se encontró diferencia estadística significativa entre las variables distrito, sexo, raza o grupo etáreo, pero se encontró diferencia estadística significativa $(\mathrm{p}<0.05)$ entre animales con y sin historia reproductiva $(26.5$ y $8.6 \%$, respectivamente).

Palabras clave: B. canis, brucelosis canina, IDGA, B. ovis, prevalencia, zoonosis

\section{INTRODUCCIÓN}

La brucelosis canina es una enfermedad zoonótica de distribución mundial, de curso crónico, causada por Brucella canis. La presen- cia de esta bacteria fue detectada por primera vez en 1966, durante investigaciones de abortos y problemas reproductivos en un criadero de perros Beagle en los Estados Unidos de Norteamérica (Carmichael y Shin, 1999).

${ }^{1}$ Práctica privada

${ }^{2}$ Laboratorio de Microbiología y Parasitología Veterinaria, FMV-UNMSM

${ }^{3}$ E-mail: calleson@gmail.com

${ }^{4}$ Facultad de Veterinaria y Zootecnia, Universidad Peruana Cayetano Heredia 
La enfermedad ha sido reconocida principalmente en el perro y ocasionalmente en el hombre, pero sólo el perro puede transmitir la infección. El hombre parece tener un grado considerable de resistencia natural a la infección por B. canis, y los casos reportados son generalmente debidos a exposiciones de laboratorio o por contacto directo con perros infectados (Stoenner y Kaplan, 1979).

La transmisión es, generalmente, a través del contacto con tejidos placentarios contaminados, fetos abortados, secreciones vaginales o semen de animales infectados. Se puede observar signos clínicos como abortos, mortalidad perinatal (Carmichael y Shin, 1999), dermatitis escrotal, prostatitis, epididimitis (Kirk, 1997), agrandamiento ganglionar generalizado, uveitis anterior (Jubb et al., 1991), discoespondilosis y reducción de los espacios intervertebrales (Boeri et al., 2001).

Trabajos previos en Lima mencionan un $28 \%$ de perros positivos (Reyes, 1977); sin embargo, no existen estudios recientes sobre el desarrollo de la enfermedad en la población canina. Es por este motivo que el presente estudio fue diseñado para determinar la prevalencia de brucelosis canina en una zona geográfica determ inada.

\section{Materiales y Métodos}

\section{Animales e información requerida}

El estudio se llevó a cabo en el 2004 en los distritos de Bellavista y Callao de la Provincia Constitucional del Callao. Se muestrearon perros de ambos sexos y de diversas edades, procedentes de una clínica veterinaria del Callao (Clínica 1), de una clínica veterinaria de Bellavista (Clínica 2), de una campaña de empadronamiento canino (Campaña 1) y de una campaña de salud canina (Campaña 2). Los datos recolectados incluyeron edad, sexo, raza, historial reproductivo y costumbres, como salir a parques o jardines. En el caso de perros con historial reproductivo se indagó sobre el número de cruzamientos, partos, problemas reproductivos, abortos y muertes perinatales.

En la determinación del tamaño muestral se utilizó una prevalencia referencial de 50\% por no haber estudios similares previos sobre esta enfermedad (Ahlbom y Norell, 1990). El número requerido fue de 385 animales pero se muestrearon 456 perros.

\section{Análisis de laboratorio}

Se obtuvieron muestras de sangre por punción de la vena cefálica. El suero resultante se almacenó en temperatura de congelación hasta su posterior procesamiento en el Laboratorio de Microbiología y Parasitología de la Facultad de Medicina Veterinaria, Universidad Nacional Mayor de San Marcos.

Se utilizó la prueba de Inmunodifusión en Gel de Agar (IDGA), que consiste en una reacción de precipitación en fase líquida entre el antígeno y el anticuerpo, formando bandas visibles de precipitación (Tizard, 1998). Esta técnica tiene la ventaja de emplear un antígeno de $B$. ovis que contiene un lipopolisacárido rugoso, específico para brucelas rugosas (como B. canis) y que no presenta reacciones cruzadas con otras especies de brucela en su forma lisa (Véliz et $a l .$, 1974). La IDGA es una prueba cualitativa, por lo que se consideran positivos los sueros que reaccionan con el antígeno formando la banda de precipitación dentro de 24 a 48 horas y negativos los sueros que no forman bandas de precipitación.

\section{Análisis de datos}

Se determinó la prevalencia de la brucelosis canina con intervalos de confianza del 95\%. Se usó la prueba de chi-cuadrado para evaluar la asociación de la tasa de infección con las variables distrito, sexo, raza, grupo etáreo e historial reproductivo. 
Cuadro 1. Prevalencia de brucelosis canina en dos distritos de la Provincia Constitucional del Callao (2004)

\begin{tabular}{|c|c|c|c|}
\hline & \multirow{2}{*}{ Total de animales } & \multicolumn{2}{|c|}{ Animales positivos } \\
\hline & & Número & $\% \pm \mathrm{IC}^{1}$ \\
\hline \multicolumn{4}{|l|}{ Distrito } \\
\hline Bellavista & 253 & 42 & $16.6 \pm 4.6$ \\
\hline Callao & 203 & 29 & $14.3 \pm 4.8$ \\
\hline \multicolumn{4}{|l|}{ Sexo } \\
\hline Macho & 239 & 34 & $14.2 \pm 4.4$ \\
\hline Hembra & 217 & 37 & $17.1 \pm 5.0$ \\
\hline \multicolumn{4}{|l|}{ Tipo racial } \\
\hline Cruzado & 216 & 40 & $18.5 \pm 5.2$ \\
\hline De raza & 240 & 31 & $12.9 \pm 4.2$ \\
\hline \multicolumn{4}{|l|}{ Edad (años) } \\
\hline $1-4$ & 312 & 53 & $17.0 \pm 4.2$ \\
\hline $5-8$ & 94 & 13 & $13.8 \pm 7.0$ \\
\hline $9-15$ & 50 & 5 & $10.0 \pm 8.3$ \\
\hline \multicolumn{4}{|l|}{ Historial reproductivo } \\
\hline Tiene & 177 & 47 & $26.6 \pm 6.5$ \\
\hline No tiene & 279 & 24 & $8.6 \pm 3.3$ \\
\hline Total & 456 & 71 & $15.6 \pm 3.3$ \\
\hline
\end{tabular}

${ }^{1}$ Intervalo de confianza del 95\%

\section{Resultados}

En el Cuadro 1 se aprecia la prevalencia de brucelosis canina obtenida, según el distrito de procedencia, sexo, tipo racial, edad e historial reproductivo. La prevalencia global fue de $15.6 \pm 3.3 \%$ (71 positivos de 456 perros muestreados). No hubo diferencias significativas $(\mathrm{p}>0.05)$ entre las variables bajo estudio con la tasa de infección, con excepción entre animales con historial reproductivo $(26.5,47 / 177)$ y sin dicho historial $(8.6 \%, 24 /$ $279, \mathrm{p}<0.05)$.

\section{Discusión}

La prevalencia de brucelosis canina fue similar en los distritos de Bellavista y Callao, posiblemente debido a que son distritos limítrofes, donde las características de crianza de los perros puede ser muy similar. Los perros infectados que comparten espacios con animales sanos para jugar, defecar o miccionar permiten que el riesgo de transmisión esté presente (Carmichael y Joubert, 1998; Stoenner y Kaplan, 1979).

La prueba de chi cuadrado no demostró asociación entre el sexo del animal y la positividad en la prueba, lo que concuerda con lo encontrado en estudios similares (Almeida et al., 2001; Castillo et al., 2002; Megid et al., 1999; Carmichael y Shin, 1999; Kirk, 1997); sin embargo, la infección en los machos es más difícil de tratar y eliminar con éxito, ya que generalmente se produce un secuestro de la bacteria en la próstata (Serikawa et al., 1984). Esta característica 
de la bacteria usualmente impide que la antibióticoterapia la elimine completamente, ya que pocos antibióticos llegan a la próstata con niveles terapéuticos adecuados (Maurin y Raoult, 2001).

Los perros de criaderos comerciales tienen una mayor posibilidad de infectarse con esta bacteria, debido a que se tiene una mayor actividad reproductiva que en casas de familia. Además, no siempre se hacen pruebas de brucelosis canina a los animales que ingresan al criadero y a veces se utilizan machos reproductores de otros criaderos, basándose en sus características fenotípicas pero sin hacerles pruebas diagnósticas.

El tipo racial y la edad no son factores predisponentes de la brucelosis canina (Almeida et al., 2001; Castillo et al., 2002; Megid et al., 1999; Carmichael y Shin, 1999; Kirk, 1997). Los perros pueden infectarse en cualquier etapa de su vida, aunque existe una mayor predisposición en perros jóvenes, ya que en éstos ocurre una mayor actividad reproductiva (Arthur et al., 1991). El grupo etáreo con mayor porcentaje de positivos del presente estudio aparentemente fue el más joven aunque sin haber diferencia estadística significativa con respecto a los otros dos grupos.

La actividad reproductiva es un aspecto importante en la adquisición de la infección (Nelson y Couto, 1995; Boeri et al., 2001), ya que la bacteria es eliminada en el semen y en las secreciones vaginales, convirtiéndose la vía sexual en una importante forma de transmisión (Carmichael y Joubert, 1998). En este estudio se encontró una gran diferencia en la prevalencia de B. canis entre perros positivos con historia reproductiva previa $(26.6 \%)$ y sin ésta $(8.6 \%)$.

Solo 177 de los 456 perros tenían historial reproductivo, lo que podría explicar el número relativamente bajo de perros positivos hallado en el presente estudio. Así mismo, cabe mencionar que a ninguno de los perros muestreados se le había hecho antes una prueba para brucelosis canina, lo que demuestra el desconocimiento de esta enfermedad y de otras de transmisión venérea por parte de los dueños .

\section{Conclusiones}

- Se encontró una prevalencia de brucelosis canina (B. canis) de $15.6 \pm$ $3.3 \%(71 / 456)$ en los distritos de Bellavista y Callao utilizando la prueba de Inmunodifusión en Gel de Agar (IDGA).

- Los perros con historia reproductiva tuvieron una mayor tasa de prevalencia $(26.5 \%)$ que aquellos que no la tenían $(8.6 \%, \mathrm{p}<0.05)$.

\section{Literatura Citada}

1. Ahlbom, A.; S. Norell. 1990. Introduction to modern epidemiology. $2^{\text {nd }}$ ed. p 25-27. Resources Inc. USA.

2. Almeida, A.; A. Santorelli; R. Bruzadelli. 2001. Soroepidemiologia da brucelose canina causada por Brucella canis e Brucella abortus na cidade de Alfenas, Brazil. Arq. Bras. Med. Vet. Zoo. 56: 65-70.

3. Arthur, G.; D. Noakes; H. Pearson. 1991. Reproducción y obstetricia en veterinaria. $6^{a}$ ed. p 544-545. Ed. Interamericana McGraw-Hill. España.

4. Boeri, E.; R. Iachini; M. Fernández. 2001. Un caso de brucelosis canina. Invest. Vet. 3: 183-185.

5. Carmichael, L.; J. Joubert. 1998. Transmission of Brucella canis by contact exposure. Am. J. Vet. Res. 35: 160-164.

6. Carmichael, L; S. Shin. 1999. Brucelosis canina causada por Brucella canis. Am. J. Vet. Res. 37: 220-223.

7. Castillo, V.; V. Cetrino; C. Moreno. 2002. Encuesta serólogica sobre Brucella canis en pacientes atendidos en la clínica de pequeños animales de la 
Facultad de Medicina Veterinaria y de Zootecnia de la Universidad Nacional de Colombia (Sede Bogotá). Arch. Med. Vet. 13: 22-25.

8. Jubb, K.; P. Kennedy; N. Palmer. 1991. Patología de los animales domésticos. $3^{a}$ ed. Ed. Agropecuaria Hemisferio Sur. Uruguay.

9. Kirk, $R$. 1997. Terapéutica veterinaria de pequeños animales. p. 1177-1181, 1347-1352. Ed. McGraw-Hill Interamericana. México.

10. Maurin, M.; D. Raoult. 2001. Use of aminoglycosides in treatment of infections due to intracellular bacteria. Antimicrob. Agents Ch. 45: 2977-2986.

11. Megid, J.; A. Britto; C. Moraes; N. Fava; J. Agottani. 1999. Epidemiological assessment of canine brucellosis. Arq. Bras. Med. Vet. Zoo. 51: 94-98.

12. Nelson, R.; C. Couto. 1995. Pilares de medicina interna en animales pequeños. p 665-669. Ed. Inter-Médica. Buenos Aires, Argentina.
13. Reyes, F. 1977. Diagnóstico serológico de brucelosis canina causada por Brucella canis en Lima Metropolitana. Tesis de Médico Veterinario. Facultad de Medicina Veterinaria, Univ. Nacional Mayor de San Marcos. Lima. 26 p.

14. Serikawa, T.; H. Takada; Y. Kondo. 1984. Multiplication of Brucella canis in male reproductive organs and detection of autoantibody to spermatozoa in canine brucellosis. Dev. Biol. Stand. 56: 295-301.

15. Stoenner, H.; W. Kaplan. 1979. Handbook series in zoonoses. Vol. I. p 185-191, 217-222. CRC Press. USA.

16. Tizard, I. 1998. Inmunología veterinaria. $5^{\text {a }}$ ed. p 242-248. Ed. Interamericana McGraw-Hill. México.

17. Véliz, N.; R. Rosadio; D. Barreto; D. Castagnino. 1974. Difusión en agar gel. Prueba de campo para el diagnóstico de la epididimitis a Brucella ovis. Rev. Inv. Pec. 3: 23-28. 